\title{
Marx: o ser e o fazer história
}

\section{Marx: the be and to make history}

DOI: $10.46814 /$ lajdv3n4-029

Recebimento dos originais: 01/05/2021

Aceitação para publicação: 31/06/2021

Elione Maria Nogueira Diógenes

Pós-Doutorado na área de Políticas Públicas da Educação

Professora Associada I da Universidade Federal de Alagoas (UFAL)

Endereço: Universitário A. C. Simões - BR 104, Km 97,6, s/n - Tabuleiro do Martins, Maceió - AL. 57072-970

E-mail: elionend@uol.com.br

\section{Maria Cledilma Ferreira da Silva Costa}

Doutoranda em Educação - PPGE/CEDU/UFAL

Instituição: Universidade Federal de Alagoas (UFAL)

Endereço: Rua Dr. Luiz de Mascarenhas, 18 - Edifício Terrazzos - apto. 106 - Farol, Maceió - AL. 57.055-030

E-mail: cledilma.costa@ifal.edu.br

\section{RESUMO}

Trata de uma abordagem teórica acerca de um texto clássico de Karl Marx (1818-1883), a saber: "Introdução ao método da economia política" (1982). O artigo ganha um contorno narrativo e vai tecendo um argumento a favor das teses marxistas. A ideia é demonstrar a atualidade do pensamento marxista para pensar os problemas do mundo contemporâneo. Conclui-se que o referido texto de Marx é um clássico e como tal deve ser compreendido.

Palavras-chave: Karl Marx, Método da economia política, pensamento marxista, teses, transformação social.

\begin{abstract}
This is a theoretical approach about a classic text of Karl Marx (1818-1883), namely: "The method of political economy" (1997). The article earns an outline narrative and weaves an argument in favor of the Marxist thesis. The idea is to demonstrate the relevance of Marxist thought to think about the problems of the contemporary world. We conclude that this text Marx is a classic and should be understood as such.
\end{abstract}

Keywords: Karl Marx's method of political economy, Marxist thought, theses, social transformation. 


\section{INTRODUÇÃO}

Nada SOU e tudo deveria ser. (Karl Marx).

"Caro (a) leitor (a)" antes de iniciar este texto tenho duas palavrinhas de esclarecimento que me parece serem necessárias à compreensão do que vem a seguir. A primeira, alerta quanto a minha delicada missão aqui: qual seja, analisar um texto clássico ${ }^{1}$ escrito há mais de cem anos de olho em todas as transformações que a história registra - desde o seu lançamento -, em sua contraditória e imprevisível trajetória. Segundo, tentar convencê-lo (la) a beber na forte e fértil fonte teórica de Karl Marx (1818-1883), o criador da dialética histórica materialista, não enquanto um método de apreensão apenas da realidade, mas, acima de tudo, como método de transformação do real, em que põe nas mãos humanas a capacidade de mudar o curso da história. Neste sentido, é um texto atual para ajudar na leitura e interpretação do mundo em que vivemos, principalmente no interior da educação brasileira.

Dito isto, é de bom tom prevenir que em sendo vivo, não sei se Marx concordaria com as ideias desenvolvidas aqui por uma passageira, terceiro-mundista, dessa nau universal alcunhada (oh! Insensatez!) de humanidade. Contudo, como objetivamente (e infelizmente), já não o temos cá entre nós, arrisco-me (a exemplo de tantos outros que sobre sua obra escreveram), a também destilar minhas impressões. Por desimportantes que sejam é sempre uma oportunidade de aceitar o convite feito pelo próprio em 1859 para pensar por conta própria: “- Estou, naturalmente, pressupondo leitor que queira aprender algo novo, desejoso, portanto, de pensar por sua própria conta.” (MARX, 1989, p. 4).

Com esta frase de Marx em mente proponho ao leitor: visitar ou revisitar a obra de Marx. Aqui, optei pelo texto que trata da Introdução à Economia Política escrita em meados do século XIX. Li e reli esse texto, tecendo algumas considerações a partir também de minha vivência como pesquisadora e educadora. O presente escrito tem como objetivo reacender o prazer pela leitura dos textos marxianos, portanto, não há uma conclusão em si, somente traçados instigantes sobre como uma obra pode ou não nos fazer sujeitos históricos potencialmente transformadores.

\section{MARX: ALÉM DE SEU TEMPO}

Buey (2004) ao considerar que o século XXI impõe a leitura de Marx como um clássico; diz mais do que oferece à vista em primeiro plano. Na verdade, o autor do qual trata não necessita, sobre hipótese alguma, de apresentações ou de “(...) manifestações de apreço ao Senhor diretor (...)” - só para lembrar Bandeira (1966) em "Poética". Seu nome e seu pensamento não cessam de se fazerem presentes nos escritos posteriores de outros estudiosos que o sucederam, explicitamente, em dois

1 Assumo aqui a definição de "Clássico" encontrada em Calvino (2001, p. 9): Os clássicos são aqueles livros dos quais, em geral, se ouve dizer: "Estou relendo..." e nunca "Estou lendo...". 
contornos: como fundador de uma determinada forma de pensar e fazer conhecimento social ou tem sempre alguém querendo provar que estava — ou estivera - errado em suas proposições. Seus ferrenhos opositores acabam de uma maneira ou de outra reacendendo a chama de um debate perene em torno de sua tradição intelectual particular.

Querendo ou não seus críticos mais ácidos, o escritor de o Manifesto Comunista inelutavelmente é História, e o é porque soube como nenhum outro, ser e fazer a um só tempo, a sua emblemática historicidade. Por isto, quando Buey (2004) corrobora o caráter clássico da sua obra, está a informar de um lado, que não o tratem feito a um cão morto - como o querem os novos ideólogos do capitalismo contemporâneo -, o que significa proferir que o seu pensamento continua tão ou mais vigoroso quanto o foi em seu tempo de origem. De outro, determina que o ato de ler Marx constitui-se em um exercício de formação em pleno sentido por ser um “(...) clássico da filosofia secularizada, do jornalismo vigoroso, da historiografia com ideias, da sociologia crítica, da teoria política como ponto de vista (...)" (BUEY, 2004, p. 17).

Em Marx, a simbiose crítica e revolucionária da teoria com a prática é levada as suas últimas consequências gerando a ação coletiva transformadora do mundo. Por isto, é preciso ter clareza e pertinência da obra desse clássico com o qual se deve dialogar e discutir, para evocar mais uma vez Buey. Escrevo, então, tais impressões com o sentimento preciso de quem faz e lida com a história, retomando outra expressão, ontologicamente, marxiana. Desde já, a intenção subjetiva é recolocar:

Certas ideias de sentimentos que foram criadoramente aparecendo e desenrolando, desde os espantos e as não-aceitações da juventude até as negações, desesperanças, tristezas e sonhos da utopia cada vez mais emocional e intelectualmente fundamentados e sofridos. (FÉLIX, 1998, p. 25).

O exemplar lido na tessitura deste estudo refere-se ao editado, pela Abril Cultural, em 1982, da coleção "Os economistas". A título de conhecimento, o texto se divide em quatro partes: 1. Produção; 2. A Relação Geral da Produção com a Distribuição, Troca e Consumo; 3. O Método da Economia Política; 4. Produção, Meios de Produção e Relações de Produção. Relações de Produção e Relações Comerciais. Formas de Estado e de Consciência em relação com as Relações de Produção e de Comércio. Relações Jurídicas. Relações Familiares. Nos anais da história registra-se que a Introdução [a crítica da economia política] é o marco do estudo temático em economia feito por Marx, entre os anos de 1857 a 1859. Gorender (1982) dá conta que somente em 1903 veio à luz. Outros estudiosos apontam que em 1939 foi publicado em Moscou o conjunto de textos que ficou sendo conhecido por tal título. Na visão de Gorender (1982, p. xi) “(...) é a mais extensa e a única exposição sistemática sobre a questão do método, na imensa literatura marxiana”. 
A preocupação deste trabalho é dupla, a saber: resumir as principais teses desenvolvidas pelo pensador alemão e empreender um exercício de compreensão da dialética materialista, evitando agir como o "recruta imbecil”, do qual fala Marx em "Crítica da filosofia do direito de Hegel”: “(...) que não teve até agora outra missão senão a de praticar e repetir exercícios já feitos”.

Andar pelo entretexto marxiano não é fácil. O autor puxa o leitor pela mão, no entanto, a casa é cheia de labirintos e corredores, muitos dos quais - a bem da verdade -; quase que de inacessível entrada. Você sente e pressente, e nisto permanece como que vítima de uma modorra mal definida e cheia de agravos. Mas, deixemos disto e vamos ao que interessa ao "inescapável leitor (a)". Pois bem, a trilha de acesso ao texto em questão foi aplainada de duas formas: a primeira, indo diretamente ao texto, e a segunda, recorrendo a outros estudiosos, leitores mais experimentados na abordagem marxiana, cuja reflexão tem maior pauta em torno da dialética histórico-materialista: método de Marx para apreensão do real enquanto perspectiva de sua superação revolucionária, erigindo ao mesmo tempo ciência e práxis.

No finalzinho do trabalho, caio na tentação de sintetizar as ideias centrais do texto em 13 teses elucidativas, de modo que o leitor ponha o agridoce sabor da nova dialética marxista em sua forma de pensar e viver o mundo: aprendendo permanentemente a transformá-lo na perspectiva da emancipação humana, pois isto era (penso eu) a razão dos escritos do filósofo de Thiers.

Não cabe, assim, passar em revista toda a literatura produzida em torno do materialismo histórico-dialético de Karl Marx². Para Gorender (1983, p. vii): “(...) a evolução do pensamento econômico marxiano é inseparável da elaboração da teoria do materialismo histórico”. Daí que o desafio imposto a si mesmo por Marx, a reprodução ideal de um processo real de uma determinada época histórica no sentido de, em conhecendo, aprender o caminho da superação não esta anacronizado, como diz Sartre (1972, P. 29) o “(...) pensamento de Marx é insuperável porque as circunstâncias que o engendraram não foram superadas".

$\mathrm{Na}$ Introdução, Marx põe o ledor de frente com o seu objeto de estudo: a produção material. Não é outra a sensação provocada no "respeitável leitor", senão a de que, pelas mãos do dono da casa, encontra-se no seu epicentro. Àquele provoca mais ainda este - já profundamente - magnetizado, ao soprar em seus ouvidos que se refere à “(...) produção dos indivíduos determinada socialmente (...)”. De "cara", o leitor é previamente avisado de que se trata da unidade na diversidade: a produção material realizada por indivíduos numa determinada sociedade. É inequívoco o recado!

2 Sequer tenho fôlego para tanto, vez que a obra marxiana tem alimentado um sem número de produção seja de caráter refutatório de suas teses, de adesão ou mesmo de recriação. 
Não satisfeito, o autor persiste no sopro: não interessa as "robinsonadas" do século XVIII. O caçador... O pescador... Essas tristes figuras ficcionais produzidas pela literatura oitocentista não é o "nosso foco de interesse". Até porque as análises feitas pelos historiadores da Civilização quanto ao nascimento desses mitos soam falsas, ilusórias, sem qualquer fundo de verdade. Esses mitos surgiram não como reação aos "excessos de requinte da sociedade burguesa" nem tampouco pelo "desejo sadio de um retorno a uma vida natural”. O contrato de Rousseau “(...) que relaciona e liga sujeitos independentes por natureza (...)" nada tem a ver com esse tal naturalismo. Tudo isto é “(...) aparência, aparência puramente estética (...)”.

O leitor desavisado que insistir em percorrer, abruptamente, a casa do autor corre o risco de não entender coisa nenhuma. É preciso retornar aos dois primeiros parágrafos uma, duas, três ou mais vezes na tentativa de compreender toda a riqueza conceitual do texto que se coloca já nesses primeiros parágrafos para depois responder a seguinte pergunta de uma simplicidade fundamental: o que, mesmo, quer dizer Marx?

Quando (Marx) anuncia o seu objeto de investigação na primeira linha do texto (a produção material), e em seguida esclarece que "Indivíduos produzindo em sociedade, portanto a produção dos indivíduos determinada socialmente, é por certo o ponto de partida (...)”, está fazendo o seguinte raciocínio: se os indivíduos produzem em sociedade, isto significa dizer que, também, eles são produzidos de uma determinada forma em tal sociedade. A preocupação de Marx é dupla: a produção material e a produção histórico-social a um só tempo.

Para tanto, refuta a ideologia do "indivíduo isolado" de Smith e Ricardo. A Vida e as Estranhas Aventuras de Robinson Crusoé (1719), personagem do romance célebre de Daniel Defoe (16601731) não é em definitivo a inquietação de Marx. Aceitar as "robinsonadas" significa permanecer no nível das aparências estéticas. No período em que se cria tamanho mito tem-se o desenvolvimento máximo da sociedade germinada no século XVI e plenamente amadurecida no XVIII. Esse indivíduo é “(...) produto, por um lado, da decomposição das formas feudais da sociedade e, por outro, das novas forças de produção que se desenvolveram a partir do século XVI (...)”.

Compreender esse indivíduo como natureza, somente, é incorrer numa ilusão, uma vez que não há homem unicamente natural. Marx dedica um longo parágrafo no sentido de desmistificar/desmontar esta ilusão a partir dos seguintes argumentos: a) Quanto mais se recua na história, o indivíduo tanto mais aparece dependente de um conjunto de relações sociais e de produção; b) Inicialmente, o indivíduo aparece ligado a uma família e tribo, depois se alarga sua inserção nas diferenciadas formas de comunidade ampliada; c) A ideia de "indivíduo isolado" nasce numa sociedade em que as relações sociais possuem um alto grau de desenvolvimento; e, d) Não existe indivíduo fora da sociedade. Esta ideia (a do indivíduo isolado) é tão absurda que sequer valeria a pena nela se deter. 
Porque Marx se detém no quarto enunciado e, é precisamente em oposição a ele, que monta seus argumentos primeiros? O contragolpe vem de imediato:

Nem sequer seria necessário tocar nesse ponto se essa banalidade que teve sentido e razão entre os homens do século XVIII não fosse seriamente reintroduzida na mais moderna Economia por Bastiat, Carey, Proudhon etc. (MARX, 1997, p. 15).

Aqui, Marx oferece as pistas de sua inquietação quanto ao seu tempo histórico. Como estudiosos que pretendem analisar uma determinada condição histórica moderna o fazem ressuscitando uma ilusão ultrapassada e anacrônica? Para servir a que propósitos? Pode-se antecipar a resposta: Logo, o capital seria uma relação natural, universal e eterna. As ideias que o autor desenvolve são colocadas, pois, contra um pensamento que ao se propor uma análise da realidade da sociedade capitalista burguesa do século XIX, utiliza recursos mitológicos e porque não dizer teológicos?

Para Proudhon e alguns outros, parece, por certo, agradável deduzir a origem de uma relação econômica, cuja gênese ignoram, de uma maneira histórico-filosófica; que lhes permite o recurso à mitologia, e dizer que as ideias surgiram de modo acabado na mente de Adão ou Prometeu, e postas em uso. (MARX, 1983, p. 4).

É contra o pensamento reificador da realidade que Marx se firma. Dá, pois, combate a uma análise que ao ignorar as razões históricas da ação humana acaba por mitificá-la, eternizando-a, e mais do que isto, naturalizando-a como algo dado por forças não humanas, portanto, por entes divinizados: tentam demonstrar que as relações sociais existentes são harmoniosas e eternas.

Recorrer a uma mitologia construída em tempos históricos outros da existência humana significa confundir ou dissolver todas as diferenças históricas em leis que se apliquem ao homem em geral. Dicotomizar a produção da distribuição, pondo a primeira, subordinada as leis eternas e a segunda, enquanto contingência humana é a razão de ser da ciência econômica burguesa, que Marx está empenhado em desnaturalizar:

Apresentar a produção - contrariamente à distribuição, etc. - como sujeita a leis eternas da natureza, independentes da história; o que é uma boa ocasião para insinuar que as relações burguesas são leis naturais e indestrutíveis da sociedade in abstracto. Esta a finalidade, mais ou menos consciente, de toda a manobra. (MARX, 1983, p. 12).

Nos dois primeiros e longos parágrafos da sua escrita, Marx remata as bases do seu pensar filosófico, desmontando o baldrame do pensamento de seus opositores, chamando a atenção para as ilusões encontradas em suas análises. Daí destaca dois aspectos centrais: o primeiro, a incapacidade de entender o homem enquanto produto de resultados históricos; e o segundo, a deficiência de sua base analítica que faz uso da mitologia e teologia para explicar relações historicamente determinadas. 
Cartas postas na mesa. Marx inicia o jogo. Trata, então, de explicitar o seu objeto de estudo. Em onze parágrafos seguintes discorre sobre o tema. Ao fazer isto, traz reflexões tais como: de que produção se está falando? Pode-se falar de produção geral e produção em geral? Como os economistas burgueses estudaram essas questões? Todo o seu esforço destina-se à procura das respostas para as perguntas acima assentadas. Nele, percebe-se que Marx está travando uma obstinada luta contra respostas de visão causal e, mais ainda, rejeita a naturalização e mistificação das relações historicamente humanas.

Tem-se aí não apenas o delineamento de uma metodologia, mas uma nova concepção do mundo, em que se constitui o materialismo histórico dialético cuja aplicabilidade se dá no domínio da vida social. Assim, Marx interpreta essa nova realidade engendrada no século XIX. Assim, ele entende que o melhor caminho... não é começar pelo que até então se considerava correto, isto é, pelo real e pelo concreto como faziam até então os economistas de seu tempo, fazer isto é falso porque as categorias tomadas no vazio não passam de abstrações, uma vez que as categorias são formas de ser, determinações da existência, isto é, existem concretamente e são produtos das ações humanas. Exemplificando da seguinte forma:

A população é uma abstração, se desprezarmos, por exemplo, as classes que a compõem. Por seu lado, essas classes são uma palavra vazia de sentido se ignorarmos os elementos em que repousam, por exemplo: o trabalho assalariado, o capital etc. (MARX, 1982, p. 14).

Propondo um outro caminho para se produzir conhecimento Marx estava revolucionando profundamente as bases da produção científica de seu tempo. Materialista, dialético e histórico o método de Marx firmou as colunas vertebrais da ontologia do ser social, reconhecendo uma única ciência, a "(...) ciência da história, que engloba tanto a natureza quanto o mundo dos homens (...)" (LUKÁCS, 1979, p. 15). Isto significa o que, então? Significa reconhecer que todas as relações que dizem respeito a bio-humanidade são ontologicamente históricas, que as categorias são históricas e que é preciso considerá-las concreta e materialisticamente (...) porque tratam antes de qualquer coisa de “(...) relações da vida humana, relações histórico-sociais, de concentricidade dialética. Assim,

O concreto é concreto porque é a síntese de múltiplas determinações, isto é a unidade do diverso. Por isso o concreto aparece no pensamento como o processo da síntese, como resultado, não como ponto de partida, ainda que seja o ponto de partida efetivo e, portanto, o ponto de partida também da intuição e da representação. (Ibidem).

A dialética materialista descortina três engodos presentes no modo de entendimento do real dos economistas burgueses: a) visão idealista do real; b) naturalização das relações sociais e c) desistorização da vida humana. O que implica pensar desta forma? Implica entender a realidade in 
abstracto, recorrendo a terminologia presente no texto trabalho. Implica rejeitar a contradição e o conflito, cristalizando as relações sociais, eternizando o momento presente, homogeneizando-o para as todas as épocas e lugares, enfatizando apenas as determinações comuns, pois através disto a classe burguesa mantém-se ad infinitum no poder. O que interessa a Marx não é àquilo que torna as épocas iguais entre si, mas o que as caracterizam enquanto diverso, pois é precisamente isso que está por conhecer e que os economistas de seu tempo não conseguem dar conta “(...) a diferença essencial por causa da unidade, a qual decorre já do fato de que o sujeito - a humanidade - e o objeto - a natureza são os mesmos.” (MARX, 1982, p. 4). E para ele isto ocorre porque o método que usam está equivocadamente "torto". Para tanto propõe um outro mais completo porque dialético, por compreender a realidade como necessariamente contraditória e em permanente transformação Konder (1981). Por isso vai mais longe: tira a dialética do idealismo hegeliano, aplicando-a a história material dos homens, como reflete Kosik (2002, p. 13):

A DIALÉTICA trata da "coisa em si”. Mas a "coisa em si” não se manifesta imediatamente ao homem. Para chegar à sua compreensão, é necessário fazer não só um certo esforço, mas também um détour. Por este motivo o pensamento dialético distingue entre representação e conceito da coisa, com isso não pretendendo apenas distinguir duas formas e dois graus de conhecimento da realidade, mas especialmente e sobretudo duas qualidades da práxis humanas.

A proposição ousada que faz Marx repousa no método materialista histórico-dialético como já disse em mais de um momento desta trabalho. A sua proposta resvala no método que seja capaz de reproduzir na ideia o ser e o fazer da história humana. Em hipótese alguma o nosso mais que centenário autor expõe apenas mais uma forma de conhecer o real, mas uma forma de ver o real em dois movimentos complementares e não díspares entre si: um enquanto dinâmica de representação (ideal) e outro enquanto dinâmica de concretização (material) e ambos enquanto socialmente engendrados na forma dos homens produzirem a sua própria existência.

No momento em que Marx faz da produção e da reprodução da vida humana o problema central, surge - tanto no próprio homem como em todos os seus objetos, relações, vínculos, etc. - a dupla determinação de uma insuperável base natural e de uma ininterrupta transformação social dessa base. (LUKÁCS, 1979, p. 16).

No método marxiano o próprio movimento de gestação do pensamento não aparece apartado da condição humana de sua existência material. Não há divórcio entre o ser que pensa e o ser que age, pois ambos são uma mesma coisa: resultado histórico coletivo de sua produção material e social. O sujeito que pensa é o sujeito que age que é o sujeito que se produz e se reproduz historicamente. Por fim, este se manifesta na materialidade histórica da vida dos homens na totalidade social. E como se dá isto? Por meio da categoria central das determinações históricas, o trabalho: 
Como sempre ocorre em Marx, [...] o trabalho é a categoria central, na qual todas as outras determinações já se apresentam in nuce: "O trabalho, portanto, enquanto formador de valoresde-uso, enquanto trabalho útil, é uma condição de existência do homem, independente de todas as formas de sociedade; é uma necessidade natural eterna, que tem a função de mediatizar o intercâmbio orgânico entre o homem e a natureza, ou seja, a vida dos homens ." através do trabalho, tem lugar uma dupla transformação. Por um lado, o próprio homem que trabalha é transformado pelo seu trabalho; ele atua sobre a natureza exterior e modifica, ao mesmo tempo, a sua própria natureza [...] (ibidem).

Por entender o trabalho enquanto um processo teleológico, Marx o transforma em ponto de partida de sua ontologia social. Assim, também tanto as categorias mais simples quanto as mais concretas são categorias ontológicas fundantes do ser social que se faz e se recria e se transforma. Por isto o real precisa ser respeitado pela sua materialidade dialética. Marx transforma-se então num severo crítico da produção intelectual de seu tempo. Tanto o materialismo mecanicista quanto o idealismo estéril não conseguem, ao seu ver, dar conta da realidade humana, pondo-o de lado. Por isso que para ele, o sistema filosófico criado por Hegel, onde as ideias, os pensamentos e os conceitos são os produtores por excelência da atividade humana não tem o menor sentido; nem tampouco acreditar que um tal idealismo domine a vida real dos homens, seu mundo material, suas relações reais. (Marx e Engels. A Ideologia Alemã). Daí se referir a Hegel como tendo caído “(...) na ilusão de conceber o real como resultado do pensamento (...)” (MARX, 1982, p. 14).

O real não é o resultado do pensamento como quer Hegel. O real em Marx é, ao contrário, uma totalidade historicamente determinada. É o movimento de efetivação da vida humana, é um todo portador de dialeticidade e de historicidade. O ser é histórico porque se faz enquanto tal na história. Mas como se reconhecer um ser histórico? Só através da apreensão de toda complexidade do real materializado na ação humana de transformar a natureza por meio do trabalho. Só através da representação ideal da totalidade concreta.

Lukács cria um itinerário, a partir do pensamento de Marx, do conhecimento do real, onde a totalidade tem um papel central, afirmando que esse parte,

(...) da totalidade do ser, e busca apreendê-la em todas as suas intricadas e múltiplas relações, no grau da máxima aproximação possível. Onde a totalidade não é um fato formal do pensamento, mas constitui a reprodução mental do realmente existente, as categorias não são elementos de uma arquitetura hierárquica e sistemática; ao contrário, são na realidade 'formas de ser, determinações da existência', elementos estruturais de complexos relativamente totais, reais, dinâmicos, cujas inter-relações dinâmicas dão lugar a complexos cada vez mais abrangentes, em sentido tanto extensivo quanto intensivo. (LUKÁCS, 1979, p. 28).

Síntese de muitos complexos nisto reside o real, portador de muitas mediações e relações. Para conhecê-lo é necessário considerar essa sua complexidade que compõe uma unidade, uma totalidade, uma síntese de muitos processos. Rosdolsky (2001, p. 39) precisando melhor a ideia de Marx quanto à temática aqui trabalhada, assim se refere: 
Marx demonstra aqui, antes de tudo, que "ir do abstrato ao concreto" é o único método científico adequado para "apropriar-se do concreto, reproduzindo-o como um concreto pensado". Na Introdução em uma passagem famosa, ele diz: "O concreto é concreto porque é a síntese de múltiplas determinações e, portanto, a unidade do diverso". Por isso, o pensamento só poder compreender plenamente o concreto "em um processo de síntese" ou seja, pela reconstrução progressiva do concreto a partir de suas determinações abstratas mais simples.

O concreto que Marx define como síntese de múltiplas determinações não pode para ele ser conhecido por meio do concreto ao abstrato, mas ao contrário do abstrato ao concreto, como esclarece Rosdolsky (2001, p. 40) revelando de forma magistral o próprio percurso metodológico do autor de O Manifesto Comunista:

O plano original foi concebido como um processo de síntese, efetuando repetidamente a "passagem do abstrato ao concreto e mais à frente Finalmente, o mesmo processo de "elevarse do abstrato ao concreto" se repete também no "Livro sobre o Capital".

A teoria social de Marx é, pois um composto dialético, materialista e histórico que deve servir de guia para o conhecimento do real; entendendo-o enquanto unidade do diverso, cujo “(...) caráter unitário e totalizante/totalizador, [está] embasado numa ontologia do ser social - a partir da crítica da economia política - historicamente constituído no mundo do capital." (PAULO NETTO, 2004, p. 239). Porque o concreto não é dado de imediato na sua complexidade, nas suas determinações, ele aparece apenas na sua aparência fenomênica. O grande desafio é ir desvelando a pseudoconcreticidade do real (KOSIK, 2002). A partir dessa aparência é que é possível chegar à essência do objeto. Como afirma Kosik (2002, p. 15):

O mundo da pseudoconcreticidade é um claro-escuro de verdade e engano. O seu elemento próprio é o duplo sentido. O fenômeno indica a essência e, ao mesmo tempo, a esconde. A essência se manifesta no fenômeno, mas só de modo inadequado, parcial, ou apenas sob certos ângulos e aspectos. O fenômeno indica algo que não é ele mesmo e vive apenas graças ao seu contrário. A essência não se dá imediatamente; é mediata ao fenômeno e, portanto, se manifesta em algo diferente daquilo que é. A essência se manifesta no fenômeno. O fato de se manifestar no fenômeno revela seu movimento e demonstra que a essência não é inerte nem passiva. Justamente por isso o fenômeno revela a essência. a manifestação da essência é precisamente a atividade do fenômeno.

Esse movimento contraditório e dialético entre aparência e essência e o lugar de cada um na história humana foi a grande preocupação de Marx. Revelar a pseudoconcreticidade das coisas em sua totalidade não é a mesma coisa que viver no reino da reificação. Isto é claro. O legado de Marx só tem sentido se percebermos que no traçado da aparência e da essência e na relação dialética entre os dois está a história enquanto práxis transformadora. Conclusivamente para Mandel (2005) nisto reside à atualidade do pensamento de Marx, pela unidade de dois movimentos, um teórico e o outro prático. Um trata de interpretar e o outro de transformar, mas um não se dá sem o outro nem tampouco apesar 
do outro nem ainda por meio de uma relação mecânica entre si. Primeiro não é isto e depois àquilo: os dois se dão juntos tentando apreender a unidade do diverso; as diferenças que são as particulares. $\mathrm{O}$ objetivo é explicar cientificamente o futuro social da humanidade e a realização de um projeto emancipador mais radical que alguma vez foi concebido:

O esperar e o esperado, no sujeito e no objeto respectivamente, o fenômeno do emergir como um todo não suscitou, até Marx, nenhuma abordagem global em que encontrasse um lugar, quanto mais um lugar central. (MANDEL, 2005, p. 16).

Um projeto assim tão grandioso só pode se concretizar se os humanos tiverem plena consciência de seu ser e fazer história. Das leis que regem a permanente mudança desta e das amplas possibilidades de construção coletiva desta. Só desta forma e apenas assim se faz teoria social. Não há outra possibilidade que não seja esta. Não há fora disto outra perspectiva que aponte para uma utopia que não seja ingênua, mas científica. O lugar da consciência da vida humana tecida por meio das relações de produção e considerando a totalidade e nela as categorias da contradição e da negação e da superação é imprescindível para o retorno à mudança emancipatória. Não se trata aqui de "dogmatizar" a filosofia marxista, mas de reconhecer a sua validade teórica subjetiva e objetiva para explicar e transformar os fenômenos históricos contemporâneos:

Desde Marx não existe mais investigação da verdade e nem juízo realista que possam esquivarse dos conteúdos subjetivos e objetivos da esperança do mundo - a não ser sob pena de trivialidade ou de beco sem saída. A filosofia terá consciência do amanhã, tomará o partido do futuro, terá ciência da esperança. Do contrário, não terá mais saber. (MANDEL, 2005, p. 17)

Em nenhum escrito de Marx a transformação enquanto vocação da teoria social ficou tão nitidamente advogado quanto Em Teses sobre Feuerbach, onde expôs as suas argumentações de forma breve, mas intensa. Pretendo a partir daqui (guardando as devidas proporções) apresentar, sucintamente, as principais ideias desenvolvidas por ele, destacando o que considero relevante em treze teses elucidativas ${ }^{3}$ de forma que você [leitor (a)], a quem dirijo esta trabalho, sinta-se instigado a “beber" de suas concepções indo diretamente ao texto escrito nos meados do século XIX, com a clareza de que:

Nunca há um leitor e um texto. Existe o leitor e um conjunto de mediações éticas, sociais e políticas entre o leitor e o texto. Não há um texto virgem. Não há um autor virgem. Não há um leitor virgem. (PAULO NETTO, 2006) ${ }^{4}$.

3 Com base no texto Teses sobre Feuerbach.

4 Apontamentos do curso sobre "Questões de Método em Marx e Lukács" realizado de 16 a 20 de outubro de 2006 ofertado pelo Programa de Políticas Públicas da Universidade Federal do Maranhão - UFMA. 


\section{TESE 1}

O homem é no sentido mais literal, um zonn politikon, não só animal social, mas animal que só pode isolar-se em sociedade. A produção do indivíduo isolado fora da sociedade - uma raridade que pode muito bem acontecer a um homem civilizado transportado por acaso para um lugar selvagem, mas levando consigo já, dinamicamente, as forças da sociedade - é uma coisa tão absurda como o desenvolvimento da linguagem sem indivíduos que vivam juntos e falem entre si.

\section{TESE 2}

Quando se trata, pois, de produção, trata-se da produção em um grau determinado do desenvolvimento social, da produção dos indivíduos sociais.

\section{TESE 3}

As determinações que valem para a produção em geral devem ser precisamente separadas, a fim de que não se esqueça a diferença essencial por causa da unidade, a qual decorre já do fato de que o sujeito a humanidade - e o objeto - a natureza - são os mesmos.

\section{TESE 4}

Trata-se, antes, de representar a produção - veja, por exemplo, Mill - diferentemente da distribuição, como regida por leis naturais, eternas, independentes da História; e nessa oportunidade insinuam-se dissimuladamente relações burguesas como leis naturais, da sociedade in abstrato.

\section{TESE 5}

A história nos mostra, ao contrário, a propriedade comum (entre os hindus, eslavos, os antigos celtas etc., por exemplo) como a forma primitiva, forma que, todavia, desempenhou durante muito tempo importante papel sob a figura de propriedade comunal.

\section{TESE 6}

Produção, distribuição, troca, consumo, formam assim [segundo a doutrina dos economistas], um silogismo correto: produção é a generalidade; distribuição e troca, a particularidade; consumo, a individualidade expressa pela conclusão. Há sem dúvida, nele, um encadeamento, mas é superficial. 


\section{TESE 7}

A fome é fome, mas a fome que se satisfaz com carne cozida, que se come com faca ou garfo, é uma fome muito distinta da que devora carne crua, com unhas e dentes.

\section{TESE 8}

A produção não produz, pois unicamente o objeto do consumo, mas também o modo de consumo, ou seja, não só objetiva, como subjetivamente. Logo, a produção cria o consumidor.

\section{TESE 9}

O objeto de arte, tal como qualquer outro produto, cria um público capaz de compreender a arte e de apreciar a beleza. Portanto, a produção não cria somente um objeto para o sujeito, mas também um sujeito para o objeto.

\section{TESE 10}

A produção não é apenas um meio para o consumo, nem o consumo um fim para a produção, no sentido em que cada um dá ao outro seu objeto, o objeto exterior do consumo, o consumo - o objeto idealizado da produção. De fato, cada um não é apenas intermediário do outro: cada um, ao realizar-se, cria o outro.

\section{TESE 11}

Considerar a sociedade como um único sujeito é considerá-la falsamente - especulativamente.

\section{TESE 12}

Mas, na sociedade o relacionamento do produtor com o produto, assim que este se encontre acabado, é puramente exterior e o retorno do produto ao sujeito depende das relações deste com os outros indivíduos. Não se apodera dele imediatamente. Também a apropriação imediata do produto não é a sua finalidade quando produz dentro da sociedade. Entre o produtor e os produtos se coloca a distribuição, a qual, por meio de leis sociais, determina sua parte no mundo dos produtos e interpõese, portanto, entre a produção e a distribuição.

\section{TESE 13}

O resultado a que chegamos não é que a produção, a distribuição, o intercâmbio, o consumo são idênticos, mas que todos eles são elementos de uma totalidade, diferenças dentro de uma unidade. 


\section{REFERÊNCIA BIBLIOGRÁFICAS}

BANDEIRA, Manuel. Estrela da vida inteira. Poesias Reunidas. Rio de Janeiro: José Olympio, 1966.

CARDOSO, Miriam Limoeiro. A Periodização e a Ciência da História: observação preliminares. (SP, Mimeo, 1977).

HELLER, Agnes. O Cotidiano e a História. São Paulo: Paz e Terra, 1970.

KONDER, Leandro. O que é dialética. 4a. São Paulo: Brasiliense, 1981. (Col. Primeiros Passos).

KOSIC, Karel. Dialética do Concreto. 2a. ed. Trad. de Célia Neves e Alderico Toríbio. Rio de Janeiro: Paz e Terra, 1995.

LEONTIEV, Alex. O Desenvolvimento do Psiquismo. Lisboa: Livros Horizontes, 1978.

LESSA, Sérgio. O Método. Fortaleza: UFC, Mímeo, 2001.

A Ontologia do Ser Social. Maceió: EDUFAL, 1996.

LUKÁCS, G. Per una Ontologia dell'Essere Sociale. V.II. Trd. di Alberto Scarponi. Roma: Editori Riuniti, 1976-81. (texto traduzido em português por Sérgio Lessa- texto digitado)

MARX, K. Manuscritos Econômicos e Filosóficos e outros textos escolhidos. Trad. de José Carlos Bruni... [et al]. 5a. ed. São Paulo: Nova Cultural, 1991. (Col. Os Pensadores).

UNICAMP, 1997.

O Método da Economia Política. (3a.parte). Trad. Fausto Castilho. São Paulo: IFCH/ Para a crítica da economia política. São Paulo, Abril Cultural, 1982. Coleção Os Economistas. 1982.

MARX, Karl; ENGELS, Friedrich. A Ideologia Alemã. São Paulo: Ed. Hucitec, 1987.

MARKUS, Gyorgy. Marxismo y “Antropologia”. Barcelona: Ed. Grijalbo, 1973.

. Teoria do Conhecimento do Jovem Marx. RJ: Paz e Terra, 1974.

MÜLLER, Marcos Lutz. Exposição e Método Dialético em "O Capital". In: Boletim SEAF- MARX. Minas Gerais, no. 2, 1982.

OLIVEIRA, Manfredo. "A Dialética de Marx". Palestra proferida. UFC, em Fortaleza-ce, junho, 2001.

POLITZER, George. Princípios Elementares de Filosofia. São Paulo: Ed Moraes, 1986.

TEIXEIRA, Francisco José. Pensando com Marx: Uma leitura crítico-comentada de O Capital. São Paulo: Ensaio, 1995. 
SARTRE, Jean Paul. Questions de méthode. Marxisme et existencialisme. Critique de la raison dialethique. Paris: G 